\title{
Statistical Anxiety and Achievement among University Students
}

\author{
Siti Mistima Maat ${ }^{1}$, Norhatta Mohd ${ }^{2}$, Che Nidzam Che Ahmad $^{3}$, Marzita Puteh ${ }^{3}$ \\ ${ }^{1}$ Faculty of Education, Universiti Kebangsaan Malaysia, Bangi, Selangor,Malaysia \\ ${ }^{2}$ Malaysian Institute of Information Technology, Universiti Kuala Lumpur, Kuala Lumpur, Malaysia \\ ${ }^{3}$ Faculty of Science and Mathematics, Sultan Idris Education University, Tanjong Malim, Perak, Malaysia
}

\begin{abstract}
Statistics is a critical subject for university students. Their achievement has been negatively impacted by statistical anxiety and the obligation to pass the statistics course. By predicting the achievement of 199 students from one of local higher educational institutions students using statistical anxiety, study mode, gender and programme specialization. A survey was used to select respondents from a variety of programs at a local university. A random sampling technique was applied in administering the questionnaire of Statistical Anxiety Rating Scale. The questionnaire consists of 51 items which has six factors that can be answered using Google form. The descriptive and inferential statistics were used to analyze the data. Statistics anxiety, age, gender, study mode, and program specialization all account for 27 percent of the variation in their achievement. It is possible to improve statistics teaching and learning among university students, despite the fact that the percentage is relatively small. Academic background and previous work experience are important factors to consider when conducting future research with profound statistical understanding.
\end{abstract}

Keywords - statistics, university, students, anxiety.

DOI: $10.18421 /$ TEM111-53

https://doi.org/10.18421/TEM111-53

Corresponding author: Siti Mistima Maat,

Faculty of Education, Universiti Kebangsaan Malaysia,

Bangi, Selangor,Malaysia.

Email: sitimistima@ukm.edu.my

Received: 15 December 2021.

Revised: 09 February 2022.

Accepted: 15 February 2022.

Published: 28 February 2022.

(c) BY-NC-ND (C) 2022 Siti Mistima Maat et al; published by UIKTEN. This work is licensed under the Creative Commons Attribution-NonCommercial-NoDerivs 4.0 License.

The article is published with Open Access at https://www.temjournal.com/

\section{Introduction}

Statistical education in Malaysia began in the third year of primary school, when students were introduced to the concepts of averages and other statistical topics through the use of tables and charts. They learn from descriptive statistics that covers graphical representation to the application of statistical reasoning. Having said that, when moving to the tertiary level then, almost all social and pure science specializations include at least one statistics course for the students gain basic. Statistics is considered to be an important practice for university students who are involved in research, and has thus become a compulsory course for students in some institutions. For similar reasons, undergraduate students in the United States have to complete a fundamental statistics course as a condition of graduation [11]. In comparison to other fields of study, statistics education has advanced to the status of a new knowledge discipline [8]. In all higher education institutions, statistics is offered as prerequisite for other courses [1]. Students are required to take statistics courses in order to prepare them for the upcoming subjects like final year project. This is due to the fact that statistics are used in research studies, and specifically in their research, which explains why.

Statistical knowledge, on the other hand, should not be restricted to students alone; the general public should be aware of statistical concepts that are used in everyday life. People have to have a statistical education in order to be able to extract information from the data that they receive for analysis. Probability and global economic fluctuations, as well as other statistical concepts, are most likely at the heart of all current information. In our daily lives, we are exposed to a wide range of situations in which statistical data is used to make decisions.

This has consequences for students' statistics result, which is important to be applied at master or doctorate level. Anxiety, on the other hand, is one of the most influential elements among students. Not 
surprisingly, there is a great deal of fear in the education community today. Statistics fear is another barrier that stops students from learning and comprehending the notion of statistics [3], [4]. When comparing online students to college students at the beginning of the semester, it was discovered that they experienced higher levels of anxiety [7].

It has been reported that the majority of university students, particularly those studying medicine and social sciences, have difficulty enrolling in statistics courses. Students who have difficulty with these statistics will do everything they can to avoid taking this course or to postpone it to the following semester [14]. Students frequently attempt to avoid taking a statistics course, but they are forced to do so when they are required to complete a final year research project for their degree. According to a study conducted by [14], undergraduate students who have high levels of anxiety in statistics have a negative relationship with their performance. At least 80 percent of students demonstrate a decline in academic performance in statistics courses [26]. It is because of this that they are denied admission to the statistics class because they have been influenced by their peers who have negative attitudes toward statistics education. The fact that certain students have difficulty with challenging statistics courses has been noticed. This has been observed to be due to the students' perceptions of the course as well as their intrapersonal characteristics related with the course. Students who have negative perceptions are more likely to have low levels of confidence and high levels of anxiety than other students.

Anxiety, fear, and insecurity when dealing with statistics are the main concerns for statisticians in this study, according to the findings. They also include feelings of anxiety in the classroom, when taking exams, and even when deciding on the most appropriate statistical method to use, such as when assigning and analyzing research data, among other things. Anxiety is associated with feelings of unease as well as taking decisive action. In addition, someone suffering from anxiety has a low tolerance for discomfort and does easy acts with little thought. For example, students may attempt to put off studying statistics because they are concerned that it will have an adverse effect on their performance [25]. They will put off their assignments out of fear of failing, which can sometimes result in a positive relationship between statistical anxiety and performance. This is supported by the findings of a study [36]. Fourteen and one-seventh percent of undergraduate students admitted delaying their assignments.

An Iranian study, we found that students who have high aspirations for success, particularly in mathematics and statistics, have lower levels of anxiety than their peers [13]. This is because they recognize the importance of understanding mathematics and statistics. By having negative attitude toward statistics, then it is possible that this will indirectly influence students' learning [38]. Student's low self-confidence can result from a high level of anxiety, which can ultimately lead to a decline in their academic performance [1]. An additional factor that influences statistics anxiety is race; Malay students, in comparison to other students, are more concerned when statistics class activities are carried out. According to the findings of [35], non-statistics students face a number of difficulties, one of which is the difficulty in understanding statistics theory, which is abstract and technical for students to grasp. This, however, is not limited to statistical theory, as students in mathematics are also confronted with the same problem as in statistics. When compared to definition and theorem, students are more frequently exposed to calculation.

Students from non-mathematical program used to face challenges in understanding statistics lesson [28]. Furthermore, students face difficulty with the use of mathematical symbols in statistical notes. Students' lack of confidence and concern with statistics has been exacerbated by their lack of exposure to mathematics symbols and notations from the start of their studies. Any new concepts or phrases that are introduced to pupils can be supported by a similar argument. As a result, students struggle to connect statistical theory to past knowledge and experience.

The basic concepts of mathematics or statistics that were studied as a result of this make it difficult to recall them. When students fail to grasp the concept of statistics, it has a negative impact on their overall performance. Students' interest in statistics should be assessed during the course [29] to assure progress and to motivate professors to examine and improve their teaching. This study's goal is to assess university students' statistical anxiety and predict their academic success by combining statistical anxiety, gender, age, study mode, and program type.

\section{Materials and Method}

Using a survey technique, this study was carried out in accordance with a quantitative approach. It is necessary to determine the sample size in order to ensure that the variables under investigation can be measured accurately. In order to conduct studies on the relationship between variables, at least 30 participants are required [5]. The sample size was also considered in order to build an acceptable model using structural equation modelling (SEM). It is recommended that when there are approximately five 
latent constructs, a sample size of 100 should be used, according to [9]. A method of determining sample size using the recommendation has also been proposed based on the findings of the [9] study. This study has therefore met or exceeded the minimum sample size suggested by [5], which is 199 students, as well as the maximum sample size suggested by [5].

Following the determination of the sample size, the researcher chose the most appropriate sampling technique for the study based on the objectives of the study. The advantage of convenient sampling is that it allows for easy communication between the samples and the researchers [5]. So, the researcher requested permission from the lecturer of statistics class to conduct the survey using random sampling technique.

Several data screening and cleaning processes were carried out prior to the analysis to ensure that only the most relevant data were entered into the SPSS. The use of descriptive statistics was used to determine the level of statistical anxiety experienced by the participants. As a result, prior to starting the research, all statistical assumptions for multiple linear regression were met.

The Statistical Anxiety Rating Scale (STARS) and the semester examination for the statistics course were utilized to collect data. There were questions on topics ranging from descriptive statistics to inferential statistics, and they were all presented in a subjective format. [34] is the Statistical Anxiety Rating Scale, which was used to develop the statistical anxiety surveys (STARS). The researchers used STARS versions that had been reviewed by [10] in their study. Some of the terms in STARS have been modified to better suit the needs of students in the United Kingdom, for example.

Although the researchers altered item 9 to ensure that students understood the meaning of the sentence, they did so to ensure that they did so. The STARS exam consisted of 51 questions organized into six primary components, each of which was rated on a Likert scale from 1 to 5, with the highest score being the best. Specifically, there were six factors including description of anxiety, fear of the statistics teacher, fear of asking for help, computational self-concept, as well as anxieties about class and exams.

In order to expedite the translation process, we used back-to-back translation, as suggested by [32] and [33]. The researcher translated the survey using back to back technique and had it checked by linguists and statisticians to ensure that the participants understood the survey items. In order to ensure that no meanings of the statements differed from their actual meanings, the researcher translated them back into English. The researcher also took into consideration expert reviews to ensure that the survey's quality could be improved, as well as to assess students' attitudes toward and concern about statistics, among other things. Then the instrument was validated for the usage purposes in the actual study.

Table 1. Factors and Items of STARS

\begin{tabular}{|c|c|c|}
\hline Factor & $\mathrm{n}$ & Items \\
\hline $\begin{array}{l}\text { Description of } \\
\text { anxiety }\end{array}$ & 11 & $\begin{array}{l}2,5,6,7,9,11,12 \\
14,17,18,20\end{array}$ \\
\hline Worth of statistics & 16 & $\begin{array}{l}24,26,27,28,29,33 \\
35,36,37,40,41,42, \\
45,47,49,50\end{array}$ \\
\hline $\begin{array}{l}\text { Fear of statistics } \\
\text { teacher }\end{array}$ & 5 & $30,32,43,44,46$ \\
\hline $\begin{array}{l}\text { Fear of asking } \\
\text { help }\end{array}$ & 4 & $3,16,19,23$ \\
\hline $\begin{array}{l}\text { Computational } \\
\text { self-concept }\end{array}$ & 7 & $\begin{array}{l}25,31,34,38,39,48, \\
51\end{array}$ \\
\hline $\begin{array}{l}\text { Test and class } \\
\text { anxiety }\end{array}$ & 8 & $\begin{array}{l}1,4,8,10,13,15,21, \\
22\end{array}$ \\
\hline
\end{tabular}

According to the results of the analysis, the reliability of STARS is 0.96 , which is considered to be very good and acceptable [7]. On the other hand, as indicated in Table 2, STARS constructions have the greatest Cronbach alpha reliability of 0.93 , while the others range from 0.87 to 0.90 .

Table 2. Reliability of STARS factors

\begin{tabular}{lcc}
\hline \multicolumn{1}{c}{ Factor } & $\begin{array}{c}\text { The } \\
\text { Cronbach } \\
\text { alpha value }\end{array}$ & $\begin{array}{c}\text { The } \\
\text { Cronbach } \\
\text { alpha value } \\
\text { for STARS }\end{array}$ \\
\hline Test and class anxiety & 0.90 & \\
Description of anxiety & 0.91 & \\
Worth of statistics & 0.93 & 0.96 \\
Fear of statistics teacher & 0.79 & \\
Fear of asking help & 0.88 & \\
Computational self-concept & 0.87 & \\
\hline
\end{tabular}

Following validation by two professionals in statistics teaching and research, the instrument was administered through Google Form. Next, the data was subjected to the clean and screen processes, and the data was analyzed using the SPSS version of software. In order to answer the research questions, descriptive and inferential statistics were employed. The dependent variables were then subjected to normality testing in order to proceed with the appropriate inferential statistics in the following step. In order to be considered normal, the distribution has to be symmetrical at the mean and have a bell-shaped shape [9]. Due to the fact that this study made use of multiple linear regression, it is also considered essential to check for the presence of outliers. All of the statistical assumptions that were made when using multiple linear regression have been met. 


\section{Respondent Profile}

Table 3 shows that $77.4 \%$ of students are female, with most participating in full-time programs $(60.3$ percent). The survey was completed by 199 students, with the majority getting a CGPA between 3.00 and 3.74 , and only 4.5 percent earning less than 2.99 . In addition to mathematics and scientific education university students from 22 other specialized programs attended this event. Due to the fact that the instrument was distributed via a Google form link, there were some instances of samples being repeated. This problem was resolved as a result of the cleaning and screening process that took place before the data analysis was carried out.

Table 3. Respondents' Profile

\begin{tabular}{|c|c|c|c|}
\hline $\begin{array}{l}\text { Demographic } \\
\text { Profile }\end{array}$ & & Frequency & $\begin{array}{c}\text { Percentage } \\
(\%)\end{array}$ \\
\hline \multirow[t]{2}{*}{ Gender } & Male & 45 & 22.6 \\
\hline & Female & 154 & 77.4 \\
\hline \multirow[t]{2}{*}{ Study mode } & $\begin{array}{l}\text { Full time } \\
\text { basis }\end{array}$ & 79 & 39.7 \\
\hline & $\begin{array}{l}\text { Part time } \\
\text { basis }\end{array}$ & 120 & 60.3 \\
\hline \multirow{4}{*}{$\begin{array}{c}\text { Cumulative } \\
\text { Grade Point } \\
\text { Average }\end{array}$} & & & \\
\hline & $3.75-4.00$ & 31 & 15.6 \\
\hline & $3.00-3.74$ & 159 & 79.9 \\
\hline & $\begin{array}{c}\text { Less than } \\
2.99\end{array}$ & 9 & 4.5 \\
\hline
\end{tabular}

\section{Findings}

There are 51 items with a Likert scale of 1 to 5 , with 1 representing "Strongly Disagree" and 5 representing "Strongly Agree." The lowest possible score is 51, and the highest possible score is 255 . Table 4 shows the results of the descriptive analysis of STARS, which shows that the mean score of STARS is 161.40 with a standard deviation of 32.30 .

Table 4. Descriptive Analysis of STARS

\begin{tabular}{lc}
\hline \multicolumn{1}{c}{ Descriptive Statistics } & Value \\
\hline Mean & 161.40 \\
Standard Deviation & 32.30 \\
Minimum & 51.00 \\
Maximum & 255.00 \\
\hline
\end{tabular}

As shown in Table 5, the scores of STARTS were grouped into three divisions; score from 51 to 119 (low), 120 to 187 (moderate) and 188 to 255 (high). The moderate level indicates that the students' anxiety is manageable, while students in high group are worried about statistics, and the lower level indicates that the students feel easy learning statistics.
Table 5. Level of STARS Category among Respondents

\begin{tabular}{ccc}
\hline Category & Frequency & Percentage $(\%)$ \\
\hline Low & 22 & 11.1 \\
Medium & 138 & 69.3 \\
High & 39 & 19.6 \\
Total & 199 & 100.0 \\
\hline
\end{tabular}

Next, a multiple linear regression was used predict university achievement based on statistical anxiety, age, gender, study mode and type of program specialization which stated that only study mode was considered as a significant predictor, $\mathrm{F}(5,178)=$ $13.14, \mathrm{p}<0.005, \mathrm{R}^{2}=27.0 \%$. This indicates that there are $73 \%$ on unexplained variation which are from other excluded variables. Respondents' predicted that is based on the following multiple linear regression equation;

Achievement $=21.34+(-.19)$ gender +0.06 age + 0.97 study mode $+(-.09)$ program specialization + 0.09 statistical anxiety.

\section{Discussion}

Anxiety over statistical outcomes was used to predict university students' success. The study also looked into how some demographic factors affect university students' statistical anxiety. As far as the respondents' criteria are concerned, this study appears to have filled a gap in the literature, particularly when compared to previous studies that focused on undergraduate students [25], [41], particularly when it comes to university students. In accordance with the findings, 69.3 percent of university students reported that they were experiencing moderate levels of statistics anxiety. This study's conclusion that statistics is not a significant barrier to university students is in line with those of [12], who used the Statistical Anxiety Questionnaire (SAQ) as their research tool.

Even though statistical anxiety as a whole is at a moderate level, the students are concerned about their test and environment. This is either due to the statistics teacher who does meet the criteria as a good teacher. This affect the classroom environment that creates the uneasy feeling when learning statistics takes place. Similarly, [29] discovered that statistical anxiety among students was caused by the educators themselves, indicating that the students' anxiety levels were raised as a result of their negative perceptions of the educators.

Furthermore, a conducive classroom helps to ensure that the teaching and learning process is carried out effectively and efficiently [20], [17]. Furthermore, a proactive teacher increases students' productivity in acquiring statistical knowledge, which indirectly lowers their levels of statistical 
anxiety in the process. Teachers should focus on teaching students how to think rather than how to memorize statistics, according to [4]. Students' overall performance and achievement are impacted by their ability to apply what they have learned in exams, which is linked to test anxiety.

Additionally, students' anxiety about statistics is related to their anxiety about taking an examination [29], [30]. It is true that the challenged to interpret statistics; analysis, as well as the duration of the examination, are related to the feeling of statistical anxiety. Students are under time constraints during examinations, which causes them to feel pressured. Students' levels of anxiety can be improved if they have a thorough understanding of statistical concepts. Additionally, students' statistical anxiety is reduced when they have a strong mathematical background. This is due to the fact that statistics tests the students' mathematical abilities in calculations as well as fundamental concepts such as regression and size effects formulas, among others. As a result, students who struggle with statistics are non-mathematical learners [3] and achieve only moderately well in mathematics [22], [24].

As a result, one of the factors identified in the [28] literature review as having an impact on students' statistics achievement is classroom and examination anxiety. Anxiety has a modest effect on performance in the classroom and on examinations, regardless of course type, whether in a lecture class or online. Students enrolled in online courses report higher levels of anxiety than students enrolled in lecture classes. This is consistent with the findings of [12], who found that the domain of anxiety towards classroom activities had the highest level of anxiety. Classroom and examination anxiety, as well as statistical interpretation, are all negatively related to component of attitude [6], [7], [8], [9]. Increased anxiety is shown to result in negative attitudes among students, according to this study. Statistics do involve graphs, tables, and charts, all of which have to be interpreted in order to provide information. If one is having trouble interpreting statistics findings and deciding which analysis to use, he/she might be suffering from interpretation anxiety [16], [28].

Moreover, [15] found that students were most concerned about interpreting statistical findings, which matched the findings of [6] on both lecture and online students. [31] found a link between exam anxiety and anxiety when interpreting statistical results. Students have to be able to read and interpret data in order to properly answer exam questions [27]. It is possible that students are concerned about statistics because they do not see the value of using statistics software or are uncomfortable using it [28], [35] High levels of anxiety when interpreting statistical results can manifest themselves as anxiety during exams.

Due to the time constraints, students are anxious rather than relaxed. Despite their enthusiasm for statistical analysis, students with experience have tendency to be more worried in taking examination than the younger students [19]. A cross-cultural study found that both American and, [21] Turkish students [18] felt anxious in class and during exams. The pressure to achieve excellent results or grades can also cause exam anxiety [3], [37]. Students have expressed a desire for teachers to use qualitative assessment rather than simply assigning letter grades to students, based on feedback they have provided. Despite the fact that there is a weak relationship between statistical anxiety and achievement, it is important to note that it does have an impact on students' overall performance in the classroom.

The most influential demographic factor on university students' achievement is statistical anxiety, followed by gender, study mode, and the least influential, the program. The study found gender differences in undergraduates' statistics anxiety [39]. As a group, men have shown the least anxiety about statistics in comparison to women, despite the fact that they are a smaller proportion of the population than women. Males are perceived to have an advantage in terms of statistical knowledge because they are more literate. The finding is consistent with the findings of [2] with only $27 \%$ variation in achievement which can be explained by the variables of the study. The remaining percentage of $73 \%$ is based on factors that are not being chosen in the study. As a result, the unexplained factors should be considered in the upcoming research [23], [40]. Depending on the study mode, there was a significant difference in anxiety towards statistics. Part-time students were more anxious than their full-time peers. Full-time students have embraced the mode as a way to review statistics class material. Furthermore, these students come from 22 different programs, which means that this factor does not have a significant impact on their statistical anxiety. It makes no difference whether they came from a pure science-based education or a social science program, their statistical anxiety was the same [20].

Their early understanding of statistics does not have an impact on what they learn at the university level, but this is due to the fact that they are studying in a different context than they were when they their statistical anxiety was the same whether they came from a pure science-based education or a social science program. Their prior knowledge of statistics has limited impact on what they learn at the university level, but they are studying in a different context than when they were undergraduates. 


\section{Conclusion}

According to the findings of this study, the level of statistical anxiety among university students is on the moderate side. In addition, factors such as gender, age, and program all play a role in achieving success. As a result, future research should examine statistical anxiety using a variety of variables and methodologies, including assessments, readiness, efficacy, and motivation. When assessing the effects of statistical anxiety, it is critical to consider the long-term relationship between variables. Nonetheless, possible interventions should be publicized so that students and teachers know what to consider when completing assignments.

After much deliberation, it was determined that the contribution made to university achievement was rather minimal. Other factors should be considered in future studies that include a larger sample of students from diverse backgrounds. For example, a case study can be conducted among those with high, moderate, and low anxiety levels at specific times, such as before and after a statistics class, focusing on how and what they feel, as well as their thoughts. Statisticians should, however, demonstrate their knowledge of statistics, particularly pedagogical content knowledge, in their teaching.

Conclusively, students should be encouraged to focus on clear-headed statistical participation rather than their own well-being. All suggested studies should be carried out successfully and documented so that they can be shared as learning resources among statisticians and statistics educators.

\section{Acknowledgements}

This research was funded by the grant of Universiti Kebangsaan Malaysia GG-2020-016

\section{References}

[1]. Arumugam, R. N. (2014). Student's Attitude towards Introductory Statistics Course at public universities using partial least square analysis. Interdisciplinary Journal of Contemporary Research in Business, 6(4), 94-123.

[2]. Beurze, S. M., Donders, A. R. T., Zielhuis, G. A., de Vegt, F., \& Verbeek, A. L. (2013). Statistics anxiety: a barrier for education in research methodology for medical students?. Medical Science Educator, 23(3), 377-384.

[3]. McGrath, A. L., Ferns, A., Greiner, L., Wanamaker, K., \& Brown, S. (2015). Reducing anxiety and increasing self-efficacy within an advanced graduate psychology statistics course. Canadian Journal for the Scholarship of Teaching and Learning, 6(1), 5 .
[4]. Bond, M. E., Perkins, S. N., \& Ramirez, C. (2012). Students' perceptions of statistics: an exploration of attitudes, conceptualizations, and content knowledge of statistics. Statistics Education Research Journal, 11(2), 6-26.

[5]. Creswell, J. W. (2002). Educational research: Planning, conducting, and evaluating quantitative (Vol. 7). Prentice Hall Upper Saddle River, NJ.

[6]. DeVaney, T. A. (2010). Anxiety and attitude of graduate students in on-campus vs. online statistics courses. Journal of Statistics Education, 18(1).

[7]. DeVaney, T. A. (2016). Confirmatory factor analysis of the statistical anxiety rating scale with online graduate students. Psychological Reports, 118(2), 565-586.

[8]. Garfield, J., \& Ben-Zvi, D. (2007). How students learn statistics revisited: A current review of research on teaching and learning statistics. International statistical review, 75(3), 372-396.

[9]. Hair, J. F., Black, W. C., Babin, B. J., and Anderson, R. E. (2010). SEM: An Introduction. In Multivariate Data Analysis: A Global Perspective (Seventh Ed, pp. 629-685). New Jersey:Pearson.

[10]. Hanna, D., Shevlin, M., \& Dempster, M. (2008). The structure of the statistics anxiety rating scale: A confirmatory factor analysis using UK psychology students. Personality and individual differences, 45(1), 68-74.

[11]. Hilton, S. C., Schau, C., \& Olsen, J. A. (2004). Survey of Attitudes Toward Statistics: Factor structure invariance by gender and by administration time. Structural Equation Modeling, 11(1), 92-109.

[12]. Koh, D., \& Zawi, M. K. (2014). Statistics Anxiety among Postgraduate Students. International Education Studies, 7(13), 166-174.

[13]. Lavasani, M. G., Weisani, M., \& Shariati, F. (2014). The role of achievement goals, academic motivation in statistics anxiety: Testing a causal model. Procedia-Social and Behavioral Sciences, 114, 933-938.

[14]. Liu, S., Onwuegbuzie, A. J., \& Meng, L. (2011). Examination of the score reliability and validity of the Statistics Anxiety Rating Scale. The Journal of Educational Enquiry, 11(1).

[15]. Williams, A. S. (2010). Statistics Anxiety and Instructor Immediacy. Journal of Statistics Education, 18(2).

[16]. Williams, A. S. (2013). Worry, intolerance of uncertainty, and statistics anxiety. Statistics education research journal, 12(1), 48-59.

[17]. Baloğlu, M., Deniz, M. E., \& Kesici, Ş. (2011). A descriptive study of individual and cross-cultural differences in statistics anxiety. Learning and Individual Differences, 21(4), 387-391.

[18]. Kesici, Ş., Baloğlu, M., \& Deniz, M. E. (2011). Selfregulated learning strategies in relation with statistics anxiety. Learning and individual Differences, 21(4), 472-477. 
[19]. Baloğlu, M. (2003). Individual differences in statistics anxiety among college students. Personality and Individual Differences, 34(5), 855-865.

[20]. Baloğlu, M. (2002). Psychometric properties of the statistics anxiety rating scale. Psychological Reports, 90(1), 315-325.

[21]. Balo_lu, M. (2004). Statistics Anxiety and Mathematics Anxiety: Some Interesting Differences I. Educational Research Quarterly, 27(3), 38-48.

[22]. Baloğlu, M. (2007). The relationship between statistics anxiety and attitudes toward statistics. Ankara University Journal of Faculty of Educational Sciences (JFES), 40(2), 23-39.

[23]. Combs, J. P., \& Onwuegbuzie, A. J. (2012). Relationships among Attitudes, Coping Strategies, and Achievement in Doctoral-Level Statistics Courses: A Mixed Research Study. International Journal of Doctoral Studies, 7.

[24]. Onwuegbuzie, A. J. (2000). Attitudes toward statistics assessments. Assessment \& Evaluation in Higher Education, 25(4), 321-339.

[25]. Onwuegbuzie, A. J. (2000). Statistics anxiety and the role of self-perceptions. The Journal of Educational Research, 93(5), 323-330.

[26]. Onwuegbuzie, A. J., \& Seaman, M. A. (1995). The effect of time constraints and statistics test anxiety on test performance in a statistics course. The Journal of experimental education, 63(2), 115-124.

[27]. Hsu, M. K., Wang, S. W., \& Chiu, K. K. (2009). Computer attitude, statistics anxiety and self-efficacy on statistical software adoption behavior: An empirical study of online MBA learners. Computers in human behavior, 25(2), 412-420.

[28]. Abd Hamid, H. S., \& Sulaiman, M. K. (2014). Statistics anxiety and achievement in a statistics course among psychology students. The Journal of Behavioral Science, 9(1), 55-66.

[29]. Zimmer, J., \& Fuller, D. (1996, November). Factors affecting undergraduate performance in statistics: A review of literature. Paper presented at the annual meeting of the Mid-South Educational Research Association. Tuscaloosa, AL.

[30]. Onwuegbuzie, A. J., \& Wilson, V. A. (2003). Statistics Anxiety: Nature, etiology, antecedents, effects, and treatments--a comprehensive review of the literature. Teaching in higher education, 8(2), 195-209.
[31]. González, A., Rodríguez, Y., Faílde, J. M., \& Carrera, M. V. (2016). Anxiety in the statistics class: Structural relations with self-concept, intrinsic value, and engagement in two samples of undergraduates. Learning and Individual Differences, 45, 214-221.

[32]. Vanhoof, S., Kuppens, S., Sotos, A. E. C., Verschaffel, L., \& Onghena, P. (2011). Measuring statistics attitudes: Structure of the survey of attitudes toward statistics (SATS-36). Statistics Education Research Journal, 10(1), 35-51.

[33]. Cruise, R. J., Cash, R. W., \& Bolton, D. L. (1985, August). Development and validation of an instrument to measure statistical anxiety. In American Statistical Association Proceedings of the Section on Statistical Education (Vol. 4, No. 3, pp. 92-97).

[34]. Phua, K. (2007). How to make the learning of statistics interesting, fun and personally relevant: using progressive material as examples for in-class analysis and to raise social awareness. Radical Statistics, 95, 4.

[35]. Rodarte-Luna, B., \& Sherry, A. (2008). Sex differences in the relation between statistics anxiety and cognitive/learning strategies. Contemporary educational psychology, 33(2), 327-344.

[36]. Veloo, A., \& Muhammad, S. (2011). 'The relationship between attitude, anxiety and habit of learning with additional mathematics achievement. Asia Pacific J. Educators Edu, 26(1), 15-32.

[37]. Batanero, C., Burrill, G., \& Reading, C. (2011). Teaching statistics in school mathematicschallenges for teaching and teacher education: A joint ICMI/IASE study: the 18th ICMI study. Dordrecht: Springer.

[38]. Estrada, A., Batanero, C., \& Lancaster, S. (2011). Teachers' attitudes towards statistics. In Teaching statistics in school mathematics-Challenges for teaching and teacher education (pp. 163-174). Springer, Dordrecht.

[39]. Mandap, C. M. (2016). Examining gender differences in statistics anxiety among college students. International Journal of Education and Research, 4(6), 358-366.

[40]. Nesbit, R. J., \& Bourne, V. J. (2018). Statistics Anxiety Rating Scale (STARS) Use in Psychology Students: A Review and Analysis with an Undergraduate Sample. Psychology Teaching Review, 24(2), 101-110.

[41]. Onwuegbuzie, A. J. (2004). Academic procrastination and statistics anxiety. Assessment \& Evaluation in Higher Education, 29(1), 3-19. 